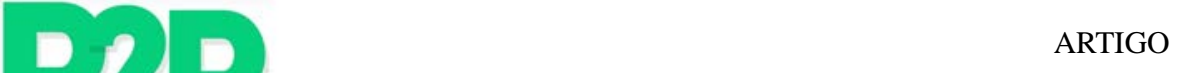

\title{
“INCLUSÃO” DIGITAL, RELAÇÕES COMUNITÁRIAS E VIGILÂNCIA
}

\author{
Patrícia Mallmann Souto Pereira \\ Doutora em Comunicação e Informação - UFRGS \\ Docente do Curso de Biblioteconomia e Gestão de Unidades de Informação - UFRJ \\ Valdir Jose Morigi \\ Doutor em Sociologia - USP \\ Docente do Curso de Biblioteconomia - UFRGS \\ Docente do Programa de Pós-Graduação em Comunicação e Informação - UFRGS
}

\begin{abstract}
Resumo
Reflete sobre as políticas públicas de inclusão digital em um contexto comunitário de favela e a questão da vigilância urbana na contemporaneidade. É baseado em resultados da tese que investigou a relação entre inclusão digital, informação e cidadania na favela Santa Marta, localizada na zona sul do Rio de Janeiro/RJ. O estudo busca apoio na fundamentação teórica de Bauman, ao analisar a questão da fusão de formas sociais e sua relação direta com o sentido de comunidade e o paradoxo entre os valores de solidariedade e do individualismo na sociedade contemporânea. Percebe que o contexto de mudança do espaço urbano da favela, com reflexo nas relações sociocomunitárias e que conduz à noção da vigilância e da insegurança, produz uma alteração no comportamento dos movimentos comunitários locais.
\end{abstract}

\section{Palabras clave}

Inclusão digital. Comunidade. Vigilância. Favela.

\section{DIGITAL “INCLUSION”, COMMUNITY RELATIONS AND SURVEILLANCE}

\begin{abstract}
Reflects on public policies of digital in a community context slum and the issue of urban surveillance in contemporary. Based on results of the thesis, which investigated the relationship between digital inclusion, information and citizenship in the favela Santa Marta, located in the southern zone of Rio de Janeiro/RJ. The study aims to support the theoretical basis of Bauman, in discussing the question of the merger of social forms and its direct relationship with the sense of community and the paradox between the values of solidarity and individualism in contemporary society. Realize that the changing context of the urban space of the slum, with an impact on social relationships and community and that leads to the notion of surveillance and insecurity, produces a change in the behavior of local community movements.
\end{abstract}

Keywords

Com Regina Digital inclusion. Community. Surveillance. Slum. 


\section{INTRODUÇÃO}

Este artigo apresenta uma reflexão sobre as políticas públicas de inclusão digital em um contexto comunitário de favela e a questão da vigilância urbana na contemporaneidade. A base empírica para a discussão está calcada nos resultados da tese de doutorado que investigou a relação entre inclusão digital, informação e cidadania na favela Santa Marta, localizada na zona sul do Rio de Janeiro/RJ (PEREIRA, 2014).

Para isso, partiu-se da ideia de que "A fusão de formas sociais e a separação entre poder e política são duas características básicas da modernidade líquida que têm óbvia repercussão na questão da vigilância [...]” (LYON, 2013, p. 14). Essas duas características podem ser claramente identificadas no contexto das mudanças que tem sofrido as favelas cariocas da zona sul do Rio de Janeiro, especificamente, a favela Santa Marta, a partir das políticas públicas voltadas a elas.

Algumas questões perpassam esse debate, como a cibercultura, através dos usos e apropriações da internet, a esfera pública discursiva na favela (vista como um espaço de resistência), que se dá em ambiente virtual e físico; a presença ostensiva do poder público policial armado no espaço da favela; a mudança da comunidade local e das relações sociocomunitárias, que tem ocorrido na favela geradas por uma série de questões, sendo uma das mais determinantes as políticas voltadas às favelas e a consequente gentrificação, gerada pelas mudanças no espaço urbano. Todo esse contexto, atravessado pelas políticas públicas de inclusão digital, interfere no imaginário da vigilância no contexto comunitário da favela.

A pesquisa de campo da tese adotou a metodologia de estudo de comunidade. A coleta de dados no campo empírico adotou três principais técnicas: pesquisa bibliográfica/documental, observação participante e entrevista em profundidade realizada com pessoas-chave na favela. A coleta dos dados foi realizada entre junho de 2012 e dezembro de 2013, em quatro momentos distintos, possibilitando consecutivas aproximações e afastamentos do campo empírico.

A favela Santa Marta possui uma formação histórica e cultural representativa de diversas favelas da zona sul carioca, sendo constituída, inicialmente, por imigrantes do interior fluminense e de Minas Gerais e, num segundo momento, do Nordeste. Os primeiros eram famílias pobres, em grande parte descendentes de ex-escravos, atraídos à então capital federal pelas oportunidades de emprego; e os segundos, igualmente, se constituíam em famílias pobres que se estabeleciam 
na cidade do Rio de Janeiro devido à grande oferta de emprego pela ampliação e construção da zona sul carioca. O início da ocupação que deu origem à formação da favela data de meados da década de 1930. A favela foi construída, em termos de infraestrutura urbana, coletivamente pelos moradores, através de mutirões. A vida na favela foi marcada por inúmeras dificuldades, decorrentes da ausência do poder público, o que acarretava na precariedade dos serviços básicos, que ficavam por conta dos moradores, e do domínio dos traficantes de droga, o que acarretava em inúmeras guerras armadas entre traficantes e Polícia Militar, sendo esta a única instância do poder público que se fazia presente na favela.

Esse contexto de formação definiu as práticas socioculturais da vida na favela, perpassadas pela religião, pelos ritmos musicais e sua cultura, como o samba e o pagode, o funk e o hip hop, pelas festividades, pelas representações sobre a favela que circulam na mídia etc. Com tudo isso, a favela possui marcas simbólicas significativas e que conferem a ela um sentido de comunidade.

O contexto atual da favela Santa Marta é afetado pela recente entrada do poder público, iniciada em 2000 e concretizada pela política de "pacificação”, através da Unidade de Polícia Pacificadora (UPP) ${ }^{1}$, pelas obras de infraestrutura urbana e pela implantação de serviços e projetos sociais. Apesar das melhorias, há dificuldades a serem enfrentadas, como deficiência nos serviços públicos e ameaça de remoção de uma parte da favela; além disso, há críticas pelos sujeitos locais quanto a troca de um poder armado (o do tráfico) por outro (o da polícia), sendo que discordam da necessidade de ter a vida controlada, pois isso tolhe a liberdade.

A favela Santa Marta possui características físicas e de localização que favorecem o controle por parte do poder público policial, ela é de médio porte, possui apenas duas entradas, sendo bem delimitada fisicamente, é bastante íngreme e se localiza na zona sul carioca. Por essas características, a favela foi escolhida para representar o modelo de políticas públicas voltadas a favelas que é vendido para o mundo.

Outra questão que veio junto com essas intervenções urbanas públicas foi o Santa Marta Digital, uma rede de internet wireless de acesso livre no morro para uso da comunidade. Foi implantado em março de 2009 pelo Governo Estadual do Rio de Janeiro.

\footnotetext{
1 Projeto da Secretaria Estadual de Segurança Pública do Estado do Rio de Janeiro, com o intuito de instituir polícias de proximidade (um tipo de polícia comunitária) em favelas, como forma de desarticular quadrilhas que controlam os territórios.
} 


\section{A SEGURANÇA DA COMUNIDADE E $O$ PARADOXO ENTRE SOLIDARIEDADE E INDIVIDUALIDADE}

O estudo se apoia em Bauman (2003; 2013), ao analisar a questão da fusão de formas sociais e sua relação direta com o sentido de comunidade. Conforme afirmação do autor (BAUMAN, 2003), o individualismo é uma característica dos tempos modernos. A favela Santa Marta possui um sentido forte de comunidade, ainda nos dias de hoje, sendo que foi mais presente no seu início, de luta pela sobrevivência e moradia. Nos dias atuais esse sentido está sendo significativamente alterado. Conforme Bauman, nunca existiu uma comunidade de fato, pois sendo comunidade, com o “[...] entendimento compartilhado do tipo ‘natural’ e ‘tácito’, ela não pode sobreviver ao momento em que o entendimento se torna autoconsciente, estridente e vociferante [...]” (BAUMAN, 2003, p. 17).

Uma comunidade possui três características principais, de acordo com Bauman (2003, p. 17-18) baseado em Redfield ${ }^{2}$ : a) distinção, que significa que “[...] a divisão entre 'nós’ e ‘eles’ é tanto exaustiva quanto disjuntiva, não há casos 'intermediários’ a excluir, é claro como a água quem é ‘um de nós’ e quem não é, não há problema nem motivo para confusão [...]”; b) pequenez, que significa que “[...] a comunicação entre os de dentro é densa e alcança tudo, e assim coloca os sinais que esporadicamente chegam de fora em desvantagem, em razão de sua relativa raridade, superficialidade e transitoriedade.”; c) autossuficiência, que significa que “[...] o isolamento em relação a 'eles' é quase completo, as ocasiões para rompê-lo são poucas e espaçadas.”, pois a comunidade “[...] oferece todas as atividades e atende a todas as necessidades das pessoas que fazem parte dela.”

Essas três características se unem na efetiva proteção dos membros da comunidade em relação às ameaças a suas práticas socioculturais e, "Enquanto cada um do trio estiver intacto, é muito pouco provável que a motivação para a reflexão, a crítica e a experimentação possam surgir. ” (BAUMAN, 2003, p. 18). O autor afirma que para que isso se efetivasse dependeria do bloqueio dos canais de comunicação com o resto do mundo habitado. Isso porque a unidade da comunidade é feita de homogeneidade, ou de “mesmidade”, que “[...] se evapora quando a comunicação entre os de dentro e o mundo exterior se intensifica e passa a ter mais peso que as

2 REDFIELD, Robert. The little community e peasant society and culture. Chicago: University of Chicago Press, 1971. 
trocas mútuas internas.” (BAUMAN, 2003, p. 18). Assim sendo, para ser comunidade no sentido estrito, seria necessário um isolamento do mundo exterior e uma vigília constante contra invasores e mudanças, mesmo dos de dentro, para que não se perdessem os sentidos “naturais”.

Apesar de não ser possível falar em comunidade nesse sentido exato do termo, há características de comunidades presentes em agrupamentos humanos, que possibilitam que estes sejam considerados como tal. Pode-se perceber que essas três características (distinção, pequenez e autossuficiência) estão em parte presentes no Santa Marta.

Em relação à distinção, percebe-se que esta característica ainda está bastante presente na favela, traduzida pela corriqueira citação por parte dos moradores quanto a "ser cria” ou "não ser cria” do morro, em referência a ter nascido ou não na favela. Apesar de haver abertura para o convívio com “o diferente”, “o outro”, é comum frases do tipo: “Mas ele não é cria...”, como se esse fato desmerecesse em alguma dimensão uma opinião ou ação de um sujeito. Também isso fica claro quando perguntado às pessoas se são nascidas na favela e se recebe a resposta unanimemente da mesma forma, dita com orgulho: "Sou nascido e criado”.

Reside aí um sentimento de identidade, e de status de pertencimento, relacionado ao fato de que suas famílias, e eles próprios, passaram por inúmeras dificuldades para se manter e construir a favela e, agora, se distinguem dos que não são “cria”, pois não compartilham dos mesmos conteúdos simbólicos e elementos culturais. A distinção bastante presente na favela se refere também à rede de sociabilidade, traduzida pelo fato das pessoas que nasceram nela se conhecerem desde crianças e conhecerem as famílias umas das outras. Mesmo a relação com o tráfico de drogas segue essa lógica, pois os traficantes também pertenciam ao “nós”, pois foram criados junto com os demais moradores de suas gerações.

Igualmente, na relação com os turistas, bastante presentes na favela atualmente, se percebe a característica da distinção, pela referência a eles como "gringos", sendo que são vistos como extremamente diferentes dos santa-martenses. Assim, o "gringo" não é apenas o turista estrangeiro, mas também o excessivamente diferente, o “de fora”. Outra situação que torna perceptível a presença da característica da distinção é a referência aos moradores dos bairros da cidade como pessoas “do asfalto” ou “lá de baixo” ou ainda “dos prédios”. Atualmente, a distinção é a mais presente das três características de comunidade na favela Santa Marta.

Em relação à característica de pequenez, o que torna ela presente é a prática informacional do "boca a boca", tida pelos moradores como a mais eficaz no que toca aos 
acontecimentos internos da favela. Mas a pequenez foi perdendo sua essência com a entrada do rádio, depois da televisão e, atualmente, da internet. Porém, a proximidade entre as pessoas, que marca a existência dessa característica, torna possível saber sobre tudo o que acontece na favela, desde que se queira. O fato das pessoas conhecerem umas às outras facilita essa circulação de informação na comunidade, pequena “[...] a ponto de estar à vista de todos seus membros [...]” (BAUMAN, 2003, p. 17). O que faz com que isso se perca um pouco é a entrada de novos moradores.

A característica de autossuficiência talvez seja a menos presente atualmente na favela, mas ela ainda se manifesta na solidariedade. A presença dela no passado é percebida pelo fato de haver poucas pessoas “de fora” frequentando o morro, assim como pelo fato dos serviços públicos, como fornecimento de luz, água e esgoto, não se fazerem presentes na favela, sendo os próprios moradores responsáveis pelo seu abastecimento nesse sentido. Apesar disso, a subsistência econômica sempre foi buscada fora da favela, a partir do trabalho remunerado. A questão que diz respeito à solidariedade já foi uma marca mais fortemente percebida nas relações sociais locais, quando os sujeitos sociais podiam dispor mais do apoio uns dos outros, e todos se conheciam.

Está presente atualmente um paradoxo entre a solidariedade, tão presente na construção e consolidação da favela, e a individualidade, que se torna cada vez mais corrente. A favela Santa Marta é uma comunidade “cravada” no meio de um bairro nobre da cidade, localizado perto das praias e do centro da cidade, mas que sempre esteve segregada deste. Porém, quando essa favela começa a "se misturar" um pouco mais com o bairro (e as pessoas de fora começam a entrar), o sentido de comunidade (a distinção, a pequenez e a autossuficiência) começa a se perder mais facilmente. Quanto mais a favela “virar bairro”, e menos segregada do restante da cidade e da sociedade se tornar, mais se misturará com diferentes pessoas, e menos comunidade será. Tem ocorrido, após o início das obras de urbanização e a instalação da UPP, uma modificação no perfil dos habitantes:

[...] o morro tem recebido muitos novos moradores. Em verdade, o processo seria de substituição de moradores. A especulação imobiliária tem produzido aumento significativo no custo de vida, especialmente no valor de venda e locação de imóveis. A especulação estaria sendo alimentada tanto pelos grandes eventos na cidade (Copa de 2014 e Olimpíadas de 2016) como pela política estadual de "pacificação" da comunidade, que, ao trazer segurança para os moradores, valorizou o lugar. Pessoas que moram distantes da zona sul veem 
nessa comunidade a oportunidade de morar na região e muitos moradores locais se veem sem condições materiais de continuar sustentando uma vida cada vez mais cara e acabam "empurrados” para localidades mais populares. " (IBASE; GRUPO ECO SANTA MARTA, 2012, p. 15).

Os moradores se ressentem com a percepção da diminuição da solidariedade, marca tão presente durante toda a construção da favela. Esse sentimento pode ser entendido pelo dilema apresentado por Bauman de segurança versus liberdade, e pelo medo de perder o sentido de comunidade e a segurança conferida por ela. Conforme afirma Bauman (2003, p. 129):

O medo de perder a comunidade é o medo da perda da segurança. Sentimos falta da comunidade porque sentimos falta de segurança, qualidade fundamental para uma vida feliz, mas que o mundo que habitamos é cada vez menos capaz de oferecer e mais relutante em prometer.

Para Bauman, a tendência é as comunidades se desmantelarem. Esse contexto urbano atual faz com que a favela vá se mesclando um pouco mais com a cidade, porém “[...] todas as formas sociais se desmancham mais depressa que a velocidade com que se criam novas formas." (LYON, 2013, p. 11). Havia uma construção sociocultural muito bem definida na favela, que está sendo modificada, produzindo nos sujeitos locais confusão, desconforto e insegurança, pois não conseguem compreender muito bem que rumo suas relações sociocomunitárias estão tomando.

Percebe-se o paradoxo que há entre o poder do Estado (traduzido pelas suas políticas públicas para a "melhoria" das favelas), que busca gerar uma imagem de segurança na favela, mas o faz para satisfazer às necessidades de formas sociais específicas (a elite burguesa carioca), tornando-as capazes de usufruir e ampliar seus espaços na cidade. Mas essa segurança em momento algum é pensada e planejada para satisfazer os direitos básicos de cidadania de outras formas sociais (os favelados, moradores da favela).

\section{INTERNET PÚBLICA, ARTICULAÇÃo POLÍTICO-COMUNITÁRIA E O PODER DA VIGILÂNCIA POLÍTICA}

As favelas são, por excelência, espaços de resistência pela luta ao direito à moradia e aos demais direitos humanos fundamentais. A organização e articulação dos movimentos sociais da pós-modernidade ocorrem cada vez mais via internet, tendo em vista que, "Embora [...] tenham 
em geral sua base no espaço urbano, mediante ocupações e manifestações de rua, sua existência contínua tem lugar no espaço livre da internet. ” (CASTELLS, 2013, p. 164). Os movimentos de luta em prol das favelas, da mesma forma, fazem uso ostensivo da internet para promover discussão, informação e articulação político-social. Na favela Santa Marta, igualmente, a internet se faz bastante presente como instrumento de amparo à continuidade das lutas comunitárias.

Na visão de Monteiro (2001), a internet é uma a rede virtual e constitui um canal de comunicação de abrangência global, pois possibilita uma diversidade de conexões entre internautas em escala planetária. Ao mesmo tempo, se constitui em um espaço interativo e expressão para grupos sociais “marginalizados” e/ou com poucas condições de se comunicar através das mídias tradicionais.

A favela Santa Marta é, historicamente, um espaço de agregação e articulação comunitárias de resistência. Atualmente, as formas como ocorre esse movimento foram alteradas pelo acesso a novas mídias sociais presentes na internet, mas sua essência permanece. Há basicamente dois lócus em que se dá a esfera pública discursiva na favela: um fisicamente constituído representado pelos espaços públicos da comunidade, especialmente, uma praça denomina "Cantão"; e um virtual, representado essencialmente pela rede social virtual Facebook. Em diferentes momentos da história da Santa Marta houve ainda uma esfera pública midiática, representada pelo “Jornal Eco”, pela “TV Favela” e pela “Rádio Comunitária Santa Marta”.

A partir da história da internet na favela é possível entender como se dá o imaginário da vigilância que permeia as ações comunitárias, sociais e políticas praticadas pelas lideranças locais. A primeira experiência de internet pública na Santa Marta é antiga, levando-se em conta que a popularização da internet no Brasil ocorreu mais fortemente na década de 2000. Em 1995 foi implantado pela Organização Não Governamental (ONG) Comitê para Democratização da Informática (CDI) um telecentro de capacitação em informática (CDI, 2005). No ano de 2002, foi implantado o primeiro telecentro comunitário da favela, pela ONG Rede de Informações Para o Terceiro Setor (RITS) (SALDANHA, 2006). Nenhum dos dois permanece em funcionamento atualmente. Os espaços públicos de acesso à internet na favela Santa Marta, atualmente, são: três telecentros (um em biblioteca e dois comunitários), duas lan houses e o sinal de internet wireless disponível no morro. Além disso, há outros locais que funcionam alternativamente para acesso à internet. 
Os três telecentros em funcionamento no morro se localizam na sua parte mais baixa, que oferece maior infraestrutura urbana e status socioeconômico. Os três telecentros são vinculados a órgãos governamentais. No que diz respeito às lan houses, elas apareceram na favela por volta da metade da década de 2000, e se disseminaram rapidamente pelo morro, pois havia grande demanda por esse serviço. Em final de 2013, havia apenas duas lan houses na favela, devido à grande parte das pessoas que possuíam interesse em conseguir ter um computador em sua residência, ou um telefone celular com possibilidade de acesso à internet. Esse fenômeno de diminuição do acesso à internet em lan houses e aumento no domicílio foi constatado em nível nacional pelo CGI (2013), sendo que, a partir de 2010, o acesso no domicílio passou a ser o mais citado entre os usuários da classe C; também houve aumento do acesso à internet domiciliar nas classes D e E, apesar da proporção de usuários de lan houses nessas ainda ser maior do que a de usuários domiciliares.

Quanto à internet domiciliar, ela chegou à favela no início da década de 2000, período em que as empresas de telefonia começaram a disponibilizar sinal no morro. Havia um morador que fazia diversas assinaturas de internet pela favela, em nome de pessoas que possuíam linha telefônica (com sua autorização) e criava redes para as casas próximas, a partir dessa assinatura, cobrando taxas pelo sinal. Isto é, a assinatura era feita para um ponto e desviada para outros. Nesse período, ainda muito poucas pessoas possuíam computador, mas para as que possuíam havia a possibilidade de acesso à internet domiciliar por um preço acessível. Esse serviço se manteve na favela até a implantação do sinal público de internet wireless, através do Santa Marta Digital.

Em relação à utilização da internet pública wireless, os moradores reclamam da sua lentidão e do fato dela frequentemente ficar ausente. Além disso, afirmam que em alguns locais ela não funciona ou funciona muito mal, apesar de em outros locais funcionar relativamente bem. Uma questão intrigante e instigante quanto a isso diz respeito aos relatos em relação ao sistema antigo de internet domiciliar funcionar bem, quando não havia sobrecarga da rede; e alcançar a todos os locais da favela. Também foram relatadas suspeitas acerca das ausências de sinal de internet wireless justamente em momentos em que começa a haver uma articulação comunitária mais efetiva, via Facebook geralmente, de denúncias e discussões sobre os problemas em relação à deficiência dos serviços públicos na favela e de articulações para manifestações de rua, e com outros grupos. 
Isso gera um imaginário de vigilância e controle virtuais, por parte de lideranças comunitárias, que desconfiam sobre estarem sendo vigiadas por órgãos governamentais a partir de suas práticas informacionais e comunicacionais via internet, o que faz com que optem pelo não uso da internet pública, preferindo, quando possível, possuir uma assinatura de internet privada. Independente dessas desconfianças serem apenas “teoria da conspiração” ou não, sabe-se que há tecnologia para tais ações. Além disso, é possível refletir também sobre o fato de que, de qualquer forma, não há real interesse governamental em promover uma política de inclusão digital mais efetiva, pois em relação apenas ao acesso, não há dúvida de que há condições tecnológicas para o fornecimento de um sinal de internet wireless de melhor qualidade.

Em relação à separação entre poder e política:

O poder agora existe num espaço global e extraterritorial, mas a política, que antes ligava interesses individuais e públicos, continua local, incapaz de agir em nível planetário. Sem controle político, o poder torna-se fonte de grande incerteza, enquanto a política parece irrelevante para os problemas e temores da vida das pessoas. (LYON, 2013, p. 13).

A política de inclusão digital, nesse contexto, parece deixar clara quem de fato detém o poder, tanto da vigilância como das armas e da exclusiva licença à violência. Essas "certezas” geram insegurança e desconfiança, o que reflete diretamente nas formas de ação comunitária e política, assim como de comunicação dos sujeitos.

\section{CONSIDERAÇÕES FINAIS: “NÓS” E OS “OUTROS” NO CONTEXTO DA VIGILÂNCIA}

O contexto sociocultural atual presente na favela Santa Marta está marcado pela fusão de diferentes formas sociais, comprometendo a manutenção das características de comunidade e, consequentemente, modificando as relações comunitárias e pessoais, o que é traduzido pelo paradoxo entre solidariedade e individualidade. Da mesma forma, a preservação da característica de “distinção" parece representar uma tentativa, quase desesperada, de manter a segurança da comunidade, protegida desse “Outro” que compromete a solidariedade e a agregação comunitária local. 
Sobre o poder e a política, percebe-se o exercício do primeiro, principalmente, na (ideia de) vigilância e controle das atividades político-comunitárias exercidas via internet; e da segunda na implantação da política pública de inclusão digital, que disponibiliza o acesso à internet com o pretenso objetivo de ampliar o alcance à informação, à comunicação e à participação, através das possibilidades existentes na internet.

A questão da vigilância na sociedade urbana pós-moderna, no que concerne à construção desta como uma forma de garantir a segurança, está bastante calcada no “medo do Outro”. Segundo Bauman (2013, p. 98):

[...] esse Outro que tendemos ou somos induzidos a temer [...] é um vizinho, um transeunte, um vadio, um espreitador, em última instância, qualquer estranho. [...] os moradores das cidades são estranhos entre si, e todos somos suspeitos de portar o perigo; [...] todos nós [...] queremos que as ameaças flutuantes, difusas e incontroladas, sejam condensadas e acumuladas num conjunto de "suspeitos habituais”. Espera-se que essa condensação mantenha a ameaça afastada e também, simultaneamente, nos proteja do perigo de sermos classificados como parte dela.

Há um imaginário construído, e reforçado, pela sociedade burguesa, pelo Estado e pela mídia comercial de massa de que o favelado é “o Outro", esse "Outro" detentor da violência e do perigo, que a favela representa essa tão almejada “condensação das ameaças” e, por isso mesmo, a favela e os favelados precisam ser vigiados constantemente pelo poder público armado, por câmeras de monitoramento e por quaisquer outras formas de controle. Mas e para o favelado, quem é esse “Outro”? Em geral, é o “gringo”, o “de fora”, o “do asfalto”, o “lá de baixo”, o “dos prédios”... Além disso, o policial armado também é “o Outro”, assim como o Estado, possuidor da vigilância, do controle e da violência também é “o Outro”. São de todos esses “Outros”, que adentraram seu espaço urbano, que os sujeitos locais da favela se sentem compelidos a se proteger e, talvez por isso, a perda da segurança da comunidade soa de forma tão ameaçadora. Percebe-se que todo esse contexto de mudança, que leva à noção da vigilância e da insegurança, produz uma alteração no comportamento dos movimentos comunitários na favela.

\section{REFERÊNCIAS}


BAUMAN, Zygmunt. Comunidade: a busca por segurança no mundo atual. Tradução Plínio Dentzien. Rio de Janeiro: J. Zahar, 2003.

BAUMAN, Zygmunt. Vigilância líquida: diálogos com David Lyon. Tradução: Carlos Alberto Medeiros. Rio de Janeiro: Zahar, 2013.

CASTELLS, Manuel. Redes de indignação e esperança: movimentos sociais na era da internet. Tradução: Carlos Alberto Medeiros. Rio de Janeiro: Zahar, 2013.

COMITÊ GESTOR DA INTERNET NO BRASIL (CGI). TIC domicílios e empresas 2012: pesquisa sobre o uso das tecnologias de informação e comunicação no Brasil. São Paulo, 2013. Disponível em: <http://www.cetic.br/publicacoes/2012/tic-domicilios-2012.pdf>. Acesso em: 21 ago. 2014.

COMITÊ PARA DEMOCRATIZAÇÃO DA INFORMÁTICA (CDI). Cidadania digital: como o CDI utiliza a informática e a educação para promover a inclusão social e transformar vidas. Rio de Janeiro, 2005.

INSTITUTO BRASILEIRO DE ANÁLISES SOCIAIS E ECONÔMICAS (IBASE); GRUPO ECO SANTA MARTA. Projeto cidade, mudanças climáticas e ação jovem: relatório de pesquisa-diagnóstico socioambiental do Santa Marta. Rio de Janeiro, 2012.

LYON, David. Introdução. In: BAUMAN, Zygmunt. Vigilância líquida: diálogos com David Lyon. Tradução: Carlos Alberto Medeiros. Rio de Janeiro: Zahar, 2013. p. 9-24.

MONTEIRO, L. A internet como meio de comunicação: possibilidades e limitações. In: CONGRESSO BRASILEIRO DA COMUNICAÇÃO - INTERCOM, 24, 2001, Campo Grande. Anais... Campo Grande: UNIDERP, 2001. p. 27-37. Disponível em: <www.portalrp.com.br/bibliotecavirtual/comunicacaovirtual/0158.pdf>. Acesso em: 15 ago. 2015.

PEREIRA, Patrícia Mallmann Souto. Informação, cidadania e inclusão digital: estudo de comunidade na favela Santa Marta, Rio de Janeiro/RJ. 2014. 246 f. Tese (Doutorado em Comunicação e Informação) - Faculdade de Biblioteconomia e Comunicação, Universidade Federal do Rio Grande do Sul, Porto Alegre, 2014. Orientador: Valdir Jose Morigi.

SALDANHA, Patrícia Gonçalves. Telecentro Santa Marta: uma práxis de cidadania: uma experiência comunitária rica e corajosa de resgate de território através das N.T.I.C.'s. UNIrevista, São Leopoldo, v.1, n. 3, p.1-13, jul. 2006. 